\title{
Sexting and risky sexual behaviours among undergraduate students in Botswana: An exploratory study
}

\author{
Obakeng L. Makgale \& Ilse Elisabeth Plattner \\ Department of Psychology, University of Botswana, Gaborone, Botswana
}

\begin{abstract}
Little is known about sexting behaviours among young people living in African countries. This exploratory study investigated sexting behaviours among undergraduate students in Botswana ( $N=309,64.5 \%$ female; mean age $=20.3$ years). Most participants (84.8\%) had received sexts and many (61.8\%) had sent sexts at least once in their lifetime. Reasons for sending sexts were to flirt (42.9\%), to have fun (24.6\%), and/or to initiate sexual activity (17.8\%). Only 36.7\% of the participants were worried about their sexts being forwarded to others, and 30.2\% had forwarded sexts to others. Being sexually active $(O R=4.52)$, drinking alcohol $(O R=2.52)$, and having a mother with tertiary level education $(O R=0.40)$ emerged as significant predictors of sending sexts. Among participants who had sexual intercourse at least once in their lifetime $(N=164)$, an increase in the frequency of sexting was associated with an increase in the number of sexual partners and with sex under the influence of alcohol and drugs. However, sexting behaviours were not associated with unprotected sex. The results are compared with findings from Western countries and discussed with regard to public health care and safe sex education in Botswana.
\end{abstract}

Keywords: Botswana; undergraduate students; risky sexual behaviours; sexting; young adults

\section{Introduction}

Sexting, a relatively new form of communication, refers to the exchange of sexually explicit messages or photographs ("sexts") through cell phones (Drouin, Ross, \& Tobin, 2015). Research suggests that adolescents and young adults seem to engage in sexting more than older adults (Currin, Hubach, Sanders, \& Hammer, 2016; Gámez-Guadix, Almendros, Borrajo, \& Calvete, 2015; Wiederhold, 2011). Sexting has received considerable media attention that highlights concerns with morality and with legal ramifications, particularly with regard to the exchange of sexually explicit images involving minors (Chalfen, 2009; Lippman \& Campbell, 2014). In spite of mainstream media presenting sexting as a problematic behaviour that should be avoided, Hudson, Fetro, and Ogletree (2014) revealed that more than $80 \%$ of their American undergraduate student sample had engaged in sexting at least once in their lifetime; most of them had a positive attitude towards sexting and perceived sexting to be fairly common among young people.

An increasing number of empirical studies target the prevalence of sexting and possible risk factors related to sexting, but knowledge about certain areas of sexting such as the effects of sexting on psychological well-being is still limited (Klettke, Hallford, \& Mellor, 2014). From a developmental perspective, sexting may contain more risks for adolescents than for young adults. For example, adolescence is the time where young people have their first experiences with romantic love and where they engage in new forms of emotional attachment, interpersonal trust, and self-disclosure that exclude their parents (Ott, Millstein, Ofner, \& Halpern-Felsher, 2006; Seiffge-Krenke, 2003), which all contribute to their identity formation (Erikson, 1968); during this period 
adolescents may be psychologically more vulnerable to the consequences of potential misuse and abuse of their sexts than emerging adults. The latter are more likely to be in stable romantic relationships and at the prime of their sexuality where they might enjoy sharing sexts (Levine, 2013). Research findings, mainly from among college students, indicate that many young adults who exchange "sexts" are in committed romantic relationships (Drouin \& Landgraff, 2012; Drouin, Vogel, Surbey, \& Stills, 2013; Samimi \& Alderson, 2014; Weisskirch \& Delevi, 2011). They use sexting as a medium to flirt and to have fun with their relationship partner, but also to initiate sexual activity (Henderson \& Morgan, 2011; Hudson et al., 2014). In some cases, however, intimate partners may aggressively coerce each other into sexting behaviours (Drouin et al., 2015; Van Ouytsel, Van Gool, Walrave, Ponnet, \& Peeters, 2015) and cause online sexual victimisation (Gámez-Guadix, et al., 2015).

Whether or not young people engage in sexting depends on various factors, including attachment styles and personality traits. As compared to young people with secure attachment styles, those with attachment anxiety were found to have had a more positive attitude towards sexting (Weisskirch \& Delevi, 2011), and those with avoidant attachment styles were more found to be more likely to engage in sexting behaviours (Drouin \& Landgraff, 2012). Ferguson (2011) found histrionic personality traits to be associated with sexting. Delevi and Weisskirch (2013) found that extrovert participants were more likely to send sext messages and participants scoring at neuroticism and low agreeableness were more likely to send sexually suggestive photographs. In some studies, age and gender made no difference in sexting (Benotsch, Snipes, Martin, \& Bull, 2013; Drouin \& Landgraff, 2012; Henderson \& Morgan, 2011; Samimi \& Alderson, 2014; Weisskirch \& Delevi, 2011), while in other studies males were more likely to receive sexts (Gordon-Messer, Bauermeister, Grodzinski, \& Zimmerman, 2013) or to send sexts (Delevi \& Weisskirch, 2013; Hudson et al., 2014; Silva, Teixeira, Vasconcelos-Raposo, \& Bessa 2016) than females. One of the conclusive findings is that young people who engage in sexting were more likely to be sexually active (i.e., engaging in vaginal, anal, or oral sex) than those who were not sexting (Klettke et al., 2014). Studies of the relationship between sexting and risky sexual behaviours have found that sexting was associated with condomless sex (Benotsch et al., 2013; Crimmins \& Seigfried-Spellar, 2014; Ferguson, 2011), multiple sexual partners (Benotsch et al., 2013, Dake, Price, Mazriaz, \& Ward, 2012; Dir, Cyders, \& Coskun pinar, 2013), and the use of alcohol and illicit drugs (Benotsch et al., 2013; Dake et al., 2012), which may increase the likelihood of risky sexual behaviours. Some studies, however, did not find a relationship between sexting and sexually risky behaviours (Currin et al., 2016; Gordon-Messer et al., 2013).

Most knowledge about sexting behaviour stems from studies investigating young people in North America, Europe, and Australia (for review cf. Döring, 2014; Klettke et al., 2014). Little is known as to whether findings of such studies also apply to young people living in African countries. The present study aimed to explore sexting behaviours among young people in Botswana. Botswana is an upper-middle income country in sub-Saharan Africa, approximately the size of France or the state of Texas, with a population of about 2.2 million people. Cell phones are a common means of communication across all socio-economic strata in Botswana (Lesitaokana, 2014a). As of March 2016, the Botswana Communications Regulatory Authority (2016) reported 3,460,331 mobile telephone subscriptions which exceed by far the country's total population. The present study aimed to investigate sexting behaviours among undergraduate students who have a monthly stipend that enables them to purchase cell phones (and, therefore, have access to sexting). More specifically, the Botswana government provides all academically deserving young people, regardless of their economic means, with cost-free access to tertiary education, including a living allowance (Ministry of Education and Skills Development, 2015) that enables students to obtain and communicate through cell phones. As noted by Lesitaokana (2014b), in Botswana students use cell phones to stay connected with family and friends and to access information and social media from the internet. With a high rate of human immunodeficiency virus (HIV) infections among young people (i.e., 5.2\%; UNAIDS, 2013), the study of sexting and possible association between sexting and risky sexual behaviours is pertinent in Botswana. The results should add to existing knowledge about sexting and provide parents, teachers, student counsellors, and health care providers in Botswana with some insights into factors associated with sexting behaviours.

The researchers did not find any studies that assessed sexting behaviours in Botswana. Considering the limited research on sexting in Botswana and other African countries, this study was of exploratory nature and aimed to investigate sexting behaviours in Botswana and to discuss the results in relation to sexting research conducted in Western countries. Following the example of previous sexting studies, this study focussed on factors associated with sexting that were investigated in other sexting studies. More specifically, the study aimed to explore sexting behaviours among undergraduate students in Botswana and asked to whom they sent their 
sexts, what motivated them to sext, whether they were aware of the risks of sexts being forwarded to people they did not intend to send sexts, and whether they forwarded sexts to others. The study also explored possible differences in sexting behaviours based on demographic variables, substance use, sexual activity, and the extent to which sexting was associated with risky sexual behaviours.

\section{Method}

\section{Procedure and Participants}

Data was collected from a convenience sample through a self-administered questionnaire that was distributed in four undergraduate classes attended by students from various academic programmes after approval from an ethics board at the University of Botswana. Participation in the study was voluntary and students were informed about the purpose of the study, their right to withdraw from participation, and the anonymous and confidential treatment of their responses. Three-hundred-and-nineteen (319) questionnaires were distributed and all of them were returned; however, ten questionnaires were incomplete in large part and, therefore, excluded from data analysis. The final sample was 309 participants (64.5\% female) ranging from 18 to 27 years of age ( $m e a n=$ 20.3 years, $S D=1.9)$. For the purpose of this study, those who were raised in a village or on farms and cattle posts (49.5\%) were categorised as coming from a 'rural area' and those who reported that they were raised in a town or city (50.5\%) were categorised as coming from an 'urban area'. Only $42.3 \%$ of the sample had a father who had completed tertiary level education and $49.3 \%$ had a mother who had completed tertiary education. Participants were enrolled in programmes in the Social Sciences (40.5\%), Business (26.8\%), Engineering and Technology (26.2\%), Humanities (2.3\%), Natural Sciences (2.3\%), Education (1.3\%), and the Health Sciences (0.6\%).

\section{Measures}

Sexting behaviours. Sexting behaviour (i.e., receiving and/or sending of sexually explicit text messages or photographs through a cell phone) and the frequency of sexting were measured through four questions (adapted from Ferguson, 2011): (1) "Have you ever received an erotic or nude photograph from another person?"; (2) "Have you ever sent an erotic or nude photograph of yourself to another person?"; (3) "Have you ever received a sexually suggestive message from another person?"; (4) "Have you ever texted a sexually suggestive message to another person?". For each item, response categories were " $0=$ never; 1 = at least once; 2 = occasionally; 3 = frequently". For these four items, a strong internal consistency reliability was obtained $(C r o n b a c h ' s$ alpha $=0.83)$. Based on the responses to these four questions, new variables were computed, one of them measuring frequency of sending and/or receiving sexts (with total scores ranging from 0 , where the participants answered 'never' to all four questions, to 12, where the participants answered 'frequently' to all four questions). Another variable computed on the basis of these four questions measured distinctive types of sexters (i.e., "non-sexters", "senders only", "receivers only", "two-way sexters" as differentiated by Gordon-Messer et al., 2013). The responses to the four questions were also recoded into two dichotomous variables measuring not sending vs. sending sexts and not receiving vs. receiving sexts.

Addressees of sexting. Addressees of sexting were measured through one multiple-response question, i.e., "To whom have you ever sent an erotic or nude photograph of yourself or a sexually suggestive message?"; response categories were "(1) no-one - (2) boyfriend/girlfriend - (3) casual sex partner(s) - (4) someone I just met - (5) someone I only knew online - (6) other" (adapted from Henderson \& Morgan, 2011). Participants were allowed to select all response categories that applied to them.

Motivation to sext. Motivation to sext was measured through one multiple-response question, i.e., "If you have ever sent an erotic or nude photograph of yourself or a sexually suggestive message, what motivated you to do so?"; response categories were "(1) I haven't done so - (2) it is my way of self-expression - (3) to be sexy - (4) to be fun - (5) to flirt - (6) to initiate sexual activity - (7) other" (adapted from Henderson \& Morgan, 2011); participants were allowed to select all response categories that applied to them. 
Forwarding of sexts. Forwarding of sexts was measured by one item, i.e., "Have you forwarded an erotic/nude photograph or a sexually suggestive message that you had received to someone else?" (adapted from Drouin et al., 2013). Response categories were " $0=$ No $-1=$ Yes".

Perception of the risk of sexting. Participants' perception of the risk of sexting was measured by one item, i.e., "Do you worry that your nude/erotic photographs or sexually suggestive messages could be sent to other people not intended to?" (adapted from Drouin et al., 2013). Response categories were " $0=$ No $-1=$ Yes".

Use of alcohol and illicit drugs. Participants were asked whether or not they had ever drank alcohol and whether or not they had ever used illicit drugs (i.e., "Have you ever drank alcohol?" and "Do you ever used marijuana and/or other drugs?"). Response categories were "0 = No - $1=$ Yes".

Sexual activity. Sexual activity was operationalized as having had vaginal, anal or oral sex during one's life time. Sexual activity was determined from the responses to a question that asked whether or not respondents had ever had sexual intercourse during their lifetime.

Risky sexual behaviours. Risky sexual behaviour was operationalized through five questions measuring (i) whether or not participants had engaged in unprotected sex at their last sexual intercourse (i.e., "At your last sexual intercourse did you or your partner use a condom?"), (ii) number of sexual partners over the past three months prior to the study, (iii) whether or not participants had - over the past three months - had sexual intercourse under the influence of alcohol, (iv) whether or not participants had - over the past three months had sexual intercourse under the influence of drugs and $(v)$ whether or not they had ever been diagnosed with a sexually transmitted infection (STI). The internal consistency reliability for the five questions probing into risky sexual behaviours was low (Cronbach's alpha $=0.55$ ). Given that the internal consistency reliability between the five items measuring risky sexual behaviours was low, the items were analysed separately with regard to sexting.

Demographic background. Demographic variables included gender, age, where participants were raised (urban or rural area), and educational level of parents.

\section{Data Analysis}

Data were analysed with SPSS (version 23), employing descriptive statistics, bivariate correlation analysis (using Pearson's $R$ for variables at interval/ratio measurement level, Spearman's Rho for ordinal variables, and Phi for correlations between dichotomous variables) and chi-square tests (including continuity correction for $2 \times 2$ tables) to test for associations and differences between variables. Binary logistic regression analysis was applied to determine predictors of sexting behaviours. The $5 \%$ significance level $(p \leq 0.05)$ and the $95 \%$ confidence interval were applied.

\section{Results}

\section{Sexting behaviours}

Table 1 shows that $30.1 \%$ of the participants had received sext messages at least once, $32.0 \%$ occasionally, and $19.7 \%$ frequently. Slightly fewer participants reported that they had received sext photos at least once (28.5\%), occasionally $(21.4 \%)$ or frequently $(7.1 \%)$. Similarly, $25.2 \%$ of the participants reported that they had sent sext messages at least once, $24.6 \%$ occasionally, and $10.0 \%$ frequently, while fewer (13.9\%) reported that they had sent sext photos at least once, $15.2 \%$ occasionally and $2.6 \%$ frequently.

Based on the responses to the four questions (as described in the method section), a new variable was computed measuring the frequency of sending and/or receiving sexts (with total scores ranging from $0=$ never sent or received any sext to $12=$ frequently sent and received sext photographs and sext messages). The mean score for frequency of sexting was $4.0(S D=3.1)$. When differentiating distinctive types of sexters, $61.2 \%$ were identified as "two-way sexters" (Gordon-Messer et al., 2013), i.e., they were both receivers and senders of sexts; $0.6 \%$ were senders only, $23.6 \%$ were receivers only, and $14.6 \%$ of the participants were non-sexters. 


\begin{tabular}{llrrr}
\hline & & $\mathbf{N}$ & $\mathbf{\%}$ & Mean (SD) \\
\hline Ever received sext message & Never & 56 & 18.1 & $1.53(1.01)$ \\
& At least once & 93 & 30.1 & \\
& Occasionally & 99 & 32.0 & \\
Ever received sext photo & 61 & 19.7 & \\
& Frequently & 133 & 43.0 & $0.93(0.96)$ \\
& Never & 88 & 28.5 & \\
Ever sent sext message & At least once & 66 & 21.4 & \\
& Occasionally & 22 & 7.1 & \\
& Frequently & 124 & 40.1 & $1.05(1.03)$ \\
Ever sent sext photo & Never & 78 & 25.2 & \\
& At least once & 76 & 24.6 & \\
& Occasionally & 31 & 10.0 & \\
& Frequently & 211 & 68.3 & $0.52(0.84)$ \\
& Never & 43 & 13.9 & \\
\hline
\end{tabular}

When recoding the responses to these four sexting items into two dichotomous variables measuring (i) never vs. ever received sext message and/or photograph and (ii) never vs. ever sent sext message and/or photograph, frequency results revealed that in total $84.8 \%$ of the participants had received sexts and $61.8 \%$ had sent sexts at least once in their lifetime. Participants who had received sexts were more likely to have sent sexts and vice versa $(r=.50, p=.000)$.

Of those who were sexters, $61.8 \%$ had sent their sexts to a boyfriend/girlfriend, $19.4 \%$ to casual sex partners, $6.3 \%$ to someone they only knew online, and $5.2 \%$ to someone they had "just met" (multiple responses were allowed). Among the sexters, $42.9 \%$ had sent sexts in order to flirt, to have fun (24.6\%), to initiate sexual activity $(17.8 \%)$, to be "sexy" (12.6\%) or to express themselves (6.3\%) (multiple responses were allowed).

Slightly more than a third of the participants (36.7\%) worried about the risk that sexts could be forwarded to people they did not intend to send a sext. Among the sexters, 30.2\% reported that they themselves had forwarded sexts to other people; and they were more likely to be among those who worried about their sexts being forwarded $\left(\chi^{2}(1)=32.1, p=.000\right)$.

\section{Sexting and Demographic Background}

Table 2 presents associations between sexting behaviours and demographic variables. Gender was partly associated with sexting behaviour. As compared to female participants, males were significantly more likely to have sent sexts $\left(\chi^{2}(1)=6.5, p=.008\right)$ and to have a higher frequency of sexting even though the correlation was weak $(r=.12, p=.032)$. Males and females did not differ in receiving sexts $\left(\chi^{2}(1)=0.1, p=.788\right)$. Participants who were raised in an urban area were significantly more likely to have received sexts $\left(\chi^{2}(1)=4.0, p=.045\right)$ than participants who were raised in a rural area; but they were not more likely to have sent sexts $\left(\chi^{2}(1)=2.5, p=\right.$ $.111)$ or to have a higher frequency of sexting $(r=.07, p=.239)$. While the educational level of the participants' fathers made no significant difference in sending sexts $\left(\chi^{2}(1)=1.0, p=.322\right)$, receiving sexts $\left(\chi^{2}(1)=1.3, p=.261\right)$ or frequency of sexting $(r=.12, p=.063)$, the educational level of mothers had a significant impact on sexting. Participants whose mothers had a tertiary level education were more likely to have sent sexts $\left(\chi^{2}(1)=8.5, p=\right.$ $.004)$ and to have a higher frequency of sexting $(r=.17, p=.006)$ even though the correlation was weak; but they were not more likely to have received sexts $\left(\chi^{2}(1)=2.3, p=.132\right)$ than those with a mother who had a lower level of education (Table 2). In addition, age was not significantly associated with sending sexts $(r=.09, p=.132$ ), receiving sexts $(r=.02, p=.706)$ or frequency of sexting $(r=.12, p=.054)$. 


\section{Sending sexts}

\begin{tabular}{llll} 
& $\chi^{2}(d f)$ & $\chi^{2}(d f)$ & $r$ \\
\hline Gender & $6.5(1)^{\star \star}$ & $0.1(1)$ & $0.12^{\star}$ \\
Rural vs. urban area & $2.5(1)$ & $4.0(1)^{\star}$ & 0.07 \\
Tertiary education of father & $1.0(1)$ & $1.3(1)$ & 0.12 \\
Tertiary education of mother & $8.5(1)^{\star \star}$ & $2.3(1)$ & $0.17^{\star *}$ \\
Alcohol & $7.5(1)^{\star \star}$ & $6.9(1)^{\star \star}$ & $0.38^{\star \star *}$ \\
Illicit drugs & $4.6(1)^{\star}$ & $4.9(1)^{\star}$ & $0.23^{\star \star \star}$ \\
Sexual activity & $16.0(1)^{\star \star \star}$ & $15.6(1)^{\star \star \star}$ & $0.53^{\star \star \star}$ \\
\hline
\end{tabular}

Note: ${ }^{*} p<0.05 ;{ }^{* \star} p<0.01 ;{ }^{* \star} p<0.001$

\section{Sexting and Substance Use}

Less than half of the sample (41.9\%) reported ever having had drank alcohol and $13.3 \%$ reported ever having used illicit drugs. Those who had drank alcohol were more likely to have sent $\left(\chi^{2}(1)=7.5, p=.004\right)$ and to have received sexts $\left(\chi^{2}(1)=6.9, p=.009\right)$ and to have had a higher frequency of sexting $(r=.38, p=.000)$ than participants who had never drank alcohol (Table 2). Those who had used drugs were more likely to have sent $\left(\chi^{2}(1)=4.6, p=.033\right)$ and to have received sexts $\left(\chi^{2}(1)=4.9, p=.027\right)$ and to have had a higher frequency of sexting ( $r=.23, p=.000$ ) than participants who had never used drugs (Table 2). However, the associations were only weak to moderate.

\section{Sexting and Sexual Activity}

In total, 164 participants (53.1\%) indicated that they had had sexual intercourse at least once in their lifetime. A moderate correlation suggested that with increasing age, participants were more likely to be sexually active $(r=$ $.31, p=.000)$. Compared to females, male participants were more likely to be sexually active $\left(\chi^{2}(1)=17.8, p=\right.$ $.000)$. Sexually active participants were significantly more likely to have sent sexts $\left(\chi^{2}(1)=16.0, p=.000\right)$ and to have received sexts $\left(\chi^{2}(1)=15.6, p=.000\right)$. A relatively strong correlation suggested that sexual activity was also associated with the frequency of sexting $(r=.53, p=.000$; Table 2$)$.

\section{Predictors of Sexting Behaviours}

Applying binary logistic regression analysis, two models were formulated (Table 3). The first model assumed that gender, age, place of up-bringing, level of education of father and mother, alcohol use, drug use, and sexual activity would predict whether or not participants were sending sexts. The Hosmer and Lemeshow test was not statistically significant $\left(\chi^{2}(8)=5.21, p=0.735\right)$, indicating that the variables were a good fit for the model. The results showed that only level of education of mother, alcohol use, and sexual activity increased the probability of sending sexts. The odds of sending sexts were four and a half times (OR $=4.52)$ higher for sexually active participants than for sexually non-active participants. The odds of sending a sext were two and a half times $(O R=$ 2.52) higher for participants who drank alcohol than for participants who did not drink alcohol and almost half a time more $(O R=0.40)$ for those whose mothers had a tertiary education than for those whose mothers did not have a tertiary education. Sexual activity, alcohol use, and tertiary education of mother explained between $23.9 \%$ (Cox \& Snell $R$ Square) and 33.5\% (Nagelkerke $R$ Square) of the variation.

The second model assumed that gender, age, place of up-bringing, level of education of father and mother, alcohol use, drug use, and sexual activity would predict whether or not participants would have received sexts. The Hosmer and Lemeshow test was non-significant $\left(\chi^{2}(8)=8.16, p=.418\right)$, indicating a good fit of the variables for the model. None of the variables significantly increased the probability of receiving sexts (Table 3 ). 


\section{Risky Sexual Behaviours}

In total, $29.3 \%$ of the sexually active participants reported that they had not used a condom during their last sexual intercourse and $26.2 \%$ reported that they had had two or more sexual partners during the past three months prior to the study (Table 4). An increase in the number of sexual partners was associated with lack of condom use $(r=.18, p=.020)$. With regard to the three months prior to the study, $18.9 \%$ of the participants reported having had sex after drinking "too much" alcohol and $12.8 \%$ reported having had sex under the influence of illicit drugs. Diagnosis of an STI was the least reported risky behaviour, with $8.6 \%$ of participants reporting testing positive to an STI in their lifetime.

Table 3. Binary Logistic Regression Analyses Predicting the Likelihood of Sending and Receiving Sexts $(N=309)$.

\begin{tabular}{|c|c|c|c|c|c|}
\hline & $B$ & $(S E)$ & Wald & OR $(95 \% C l)$ & $p$-value \\
\hline \multicolumn{6}{|c|}{ Not sending vs. sending sexts } \\
\hline Gender & 0.14 & 0.42 & 0.11 & $1.15(0.51,2.60)$ & 0.744 \\
\hline Age & 0.04 & 0.11 & 0.13 & $1.04(0.84,1.28)$ & 0.716 \\
\hline Urban vs. rural area & -0.12 & 0.38 & 0.10 & $0.89(0.42,1.88)$ & 0.755 \\
\hline Education Father & 0.21 & 0.46 & 0.22 & $1.24(0.50,3.04)$ & 0.641 \\
\hline Education Mother & -0.92 & 0.47 & 3.87 & $0.40(0.16,1.00)$ & 0.049 \\
\hline Alcohol use & 0.93 & 0.40 & 5.28 & $2.52(1.15,5.55)$ & 0.022 \\
\hline Drug use & 0.32 & 0.66 & 0.23 & $1.37(0.38,5.03)$ & 0.632 \\
\hline Sexual activity & 1.51 & 0.40 & 14.27 & $4.52(2.07,9.87)$ & 0.000 \\
\hline \multicolumn{6}{|c|}{ Not receiving vs. receiving sexts } \\
\hline Gender & 0.76 & 0.50 & 2.35 & $2.14(0.81,5.67)$ & 0.125 \\
\hline Age & 0.07 & 0.14 & 0.24 & $1.07(0.81,1.41)$ & 0.626 \\
\hline Urban vs. rural area & -0.31 & 0.46 & 0.44 & $0.74(0.30,1.82)$ & 0.506 \\
\hline Education Father & 0.22 & 0.55 & 0.18 & $1.24(0.42,3.65)$ & 0.692 \\
\hline Education Mother & -0.74 & 0.57 & 1.69 & $0.48(0.16,1.46)$ & 0.194 \\
\hline Alcohol use & 0.39 & 0.50 & 0.60 & $1.47(0.55,3.90)$ & 0.440 \\
\hline Drug use & 1.12 & 1.10 & 1.03 & $3.07(0.35,26.69)$ & 0.310 \\
\hline Sexual activity & 0.62 & 0.51 & 1.52 & $1.87(0.69,5.02)$ & 0.217 \\
\hline
\end{tabular}

Table 4. Risky Sexual Behaviours among Sexually Active Participants $(N=164)$.

\begin{tabular}{llrrr}
\hline & & $\mathbf{N}$ & $\mathbf{\%}$ & Mean (SD) \\
\hline Condom use at last sexual intercourse & No & 48 & 29.3 & $0.71(0.46)$ \\
& Yes & 116 & 70.7 & \\
Number of sexual partners during past three months & Zero & 30 & 18.3 & $1.08(0.65)$ \\
& One & 91 & 55.5 & \\
Sex after drinking "too much" alcohol during past three months & Two and more & 43 & 26.2 & \\
& Never & 133 & 81.1 & $0.19(0.39)$ \\
Sex under the influence of drugs during past three months & At least once & 31 & 18.9 & \\
& Never & 143 & 87.2 & $0.13(0.34)$ \\
Diagnosis of an STI (life time) & At least once & 21 & 12.8 & \\
& No & 149 & 91.4 & $0.09(0.28)$ \\
\hline
\end{tabular}

With increasing age, participants were more likely to have had sex under the influence of alcohol $(r=.17, p=$ .043 ) and drugs ( $r=.21, p=.014)$, and to have been diagnosed with an STI ( $r=.25, p=.003)$. Gender made no significant difference in the tendency to engage in any of the risky sexual behaviours.

\section{Sexting and Risky Sexual Behaviours}

As seen in Table 5, none of the sexting variables were associated with condom use at last sexual intercourse or with having been diagnosed with an STI. Receiving sexts was also not associated with any of the risky sexual behaviours. However, sending sexts was significantly associated with an increase in the number of sexual 
partners $(r=.21, p=.007)$ though the correlation was weak. An increase in the frequency of sexting was associated with an increase in the number of sexual partners $(r=.29, p=.000)$, sex under the influence of alcohol $(r=.29, p=.000)$, and sex under the influence of illicit drugs $(r=.25, p=.000)$ though the correlations were weak.

Table 5. Correlations between Sexting and Risky Sexual Behaviours (among Sexually Active Participants, $N=164$ ).

\begin{tabular}{lccccr}
\hline & $\begin{array}{l}\text { Condom } \\
\text { use }\end{array}$ & $\begin{array}{l}\text { Number of sexual } \\
\text { partners }\end{array}$ & $\begin{array}{l}\text { Sex under influence } \\
\text { of alcohol }\end{array}$ & $\begin{array}{l}\text { Sex under influence } \\
\text { of drugs }\end{array}$ & STI \\
\hline Receiving sexts & 0.03 & 0.06 & 0.02 & 0.03 & 0.08 \\
Sending sexts & 0.10 & $0.21^{* *}$ & 0.11 & 0.09 & 0.03 \\
$\begin{array}{l}\text { Frequency of } \\
\text { sexting }\end{array}$ & 0.10 & $0.29 * * *$ & $0.29 * * *$ & $0.25^{* * *}$ & 0.03 \\
\hline
\end{tabular}

Note: ${ }^{*} p<0.05 ;{ }^{* \star} p<0.01 ; * \star \star p<0.001$

Applying binary logistic regression analysis, two models were formulated (Table 6). The first model assumed that unprotected sex, number of partner, sex under the influence of alcohol and illicit drugs, and having been diagnosed with an STI would predict whether or not sexually active participants were sending sexts. The Hosmer and Lemeshow test was not statistically significant $\left(\chi^{2}(6)=5.51, p=.481\right)$, indicating that the variables were a good fit for the model. The results showed that only the variable number of partners increased the probability of sending sexts but the odds were low $(\mathrm{OR}=.20)$ and the number of partners explained only between $6.0 \%$ (Cox \& Snell $R$ Square) and 9.7\% (Nagelkerke $R$ Square) of the variation. The second model assumed that the indicators of risky sexual behaviours would predict whether or not participants would have received sexts. The Hosmer and Lemeshow test was non-significant $\left(\chi^{2}(5)=1.70, p=.890\right)$, indicating a good fit of the variables for the model. None of the risky sexual behaviours increased the probability of receiving sexts (Table 6).

Table 6. Risky Sexual Behaviours Predicting the Likelihood of Sending and Receiving Sexts $(N=164)$.

\begin{tabular}{|c|c|c|c|c|c|}
\hline & $B$ & $(S E)$ & Wald & OR $(95 \% C l)$ & $p$-value \\
\hline & \multicolumn{5}{|c|}{ Not sending vs. sending sexts } \\
\hline Condom use & -0.40 & 0.51 & 0.61 & $0.76(0.25,1.82)$ & 0.435 \\
\hline Number of sexual partners & -1.63 & 0.78 & 4.39 & $0.20(0.04,0.90)$ & 0.036 \\
\hline Sex under the influence of alcohol & -0.41 & 0.69 & 0.35 & $0.66(0.17,2.57)$ & 0.553 \\
\hline Sex under the influence of drugs & -0.27 & 0.85 & 0.10 & $1.76(0.14,4.02)$ & 0.748 \\
\hline \multirow[t]{2}{*}{ STI } & 0.24 & 0.87 & 0.08 & $1.27(0.23,6.94)$ & 0.783 \\
\hline & \multicolumn{5}{|c|}{ Not receiving vs. receiving sexts } \\
\hline Condom use & 0.26 & 0.66 & 0.15 & $1.29(0.35,4.70)$ & 0.125 \\
\hline Number of sexual partners & -0.75 & 0.85 & 0.79 & $0.47(0.09,2.49)$ & 0.626 \\
\hline Sex under the influence of alcohol & -0.39 & 0.95 & 0.17 & $0.68(0.11,4.33)$ & 0.506 \\
\hline Sex under the influence of drugs & 0.50 & 0.94 & 0.28 & $1.65(0.26,10.30)$ & 0.692 \\
\hline STI & -0.96 & 0.91 & 1.10 & $2.60(0.44,15.47)$ & 0.194 \\
\hline
\end{tabular}

\section{Discussion}

This exploratory study aimed to examine sexting behaviours among young people in Botswana. Similar to what was found among college students in Western countries (e.g., Drouin \& Landgraff, 2012; Drouin et al., 2013, Henderson \& Morgan, 2011), the results showed that undergraduate students in Botswana also engaged in sexting behaviours, and several of them sent their sexts to their boyfriend/girlfriend in order to flirt, to have fun or to initiate sexual activity. Similar to findings of previous studies, the majority of participants reported having received sexts more than having sent sexts. As pointed out by Klettke et al. (2014), such findings could be a 
result of underreporting the amount of sending sexts since research participants may assess receiving sexts as socially more acceptable than sending sexts.

Almost one third of the participants reported that they had forwarded a sext to persons that the sext was not intended for, which was higher than that observed in the study by Strassberg, Rullo, and Mackaronis (2014) where less than eight percent admitted such behaviour. Two thirds of the participants were not concerned about the possibility of their sexts being forwarded to people that they were not intended for. This result suggests that either the participants had trust in their sexting partners or, as highlighted by Chalfen (2009, p. 258), that "sexters give little or no thought to what other young people might do with the pictures".

Similar to findings of other studies (e.g. Weisskirch \& Delevi, 2011), age was not associated with sexting behaviours. This could be due to the fact that the participants were a relatively homogenous age cohort of 18 to 27 years old undergraduate students in the developmental stage of emerging adulthood (Arnett, 2000). Male and female participants did not differ in receiving sexts, however, males were more likely to have sent sexts. The latter was also found in research by Delevi \& Weisskirch (2013) and Silva et al. (2016). Perhaps such result could be understood from within culturally motivated and perceived "scripts" based on which males are expected to be the ones who initiate courtship (Seal \& Ehrhardt, 2003), which in this day and age could include sending sexts. Participants who were raised in urban areas were more likely to have received sexts than participants from rural areas. While literature has reported that rates of generally risky behaviours among young people are higher in rural areas than in urban areas (Woodward, Evans, \& Brooks, 2016), this study found that urban life exposed participants of this study more to receiving sexts than rural life. More in-depth research is needed to explore the influence of growing up in a rural vs. urban area on sexting behaviour.

The results also revealed that while the participants' father's level of education made no difference in their sexting behaviours, participants whose mother had tertiary level education were more likely to have sent sexts and to have a higher frequency of sexting than those with a mother of a lower level of education. The results could be interpreted from within the socio-cultural context of Botswana where many children grow up in femaleheaded households, in which the role of the father is diminished (Dintwat, 2010; Fako, 2005). One possible explanation could be that highly educated mothers are more likely to have the financial means to provide their children with expensive cellphone technology that may be used to send sexts. More research is needed to examine sexting behaviour and the role of the highly educated mother in the Botswana context.

One of the shortcomings of this study was not to have considered a time frame within which alcohol and substance use took place and not to have differentiated between the amount of alcohol consumed and the extent of using illicit drugs. Nonetheless, participants who had ever drank alcohol and/or ever used drugs were found to be more likely to have engaged in sexting behaviours than participants who reportedly never drank alcohol or used drugs. Similar findings have been reported by Drouin et al. (2015) and Currin et al. (2016). However, more research is needed in order to explain the associations between sexting behaviours and substance use. Perhaps young people who do not and have never consumed substances are less likely to sext because they generally tend to stay away from behaviour that could expose them to personal risks.

Although this study identified some significant differences in sexting behaviours by gender, rural vs. urban background, mothers' level of education, and use of alcohol and illicit drugs, binary logistic regression analysis showed that only sexual activity, and to a lesser extent using alcohol and mother's level of education, were significant predictors of sending sexts. When compared to participants who had never had sexual intercourse, sexually active participants were four and a half times more likely to be senders of sexts. This is consistent with findings of studies reviewed by Klettke et al. (2014). These results should be understood against the assumption that the sending of sexually explicit images and messages probably requires some form of sexual confidence stemming from sexual experiences that sexually inexperienced people are likely not to have. However, as reported by Klettke et al. (2014) and as supported by the results of this study, sexual activity explains only a small fraction of sexting, suggesting that there are other variables that determine whether or not young people engage in sexting behaviours.

While in this study sexual activity, use of alcohol, and educational level of mother appeared to predict sending sexts, none of the variables investigated could predict whether or not participants were more likely to receive 
sexts. Such results could be explained by the fact that sending sexts is an active behaviour that may be performed based on sexual experience and/or under the influence of alcohol while individuals do not necessarily play an active role when receiving sexts; individuals who may not even want to receive sexts may nonetheless receive some. Therefore, personal and situational variables may not determine whether or not someone will receive sexts.

Finally, the study sought to explore whether sexting was associated with risky sexual behaviours. While slightly more than half of the sexually active participants reported some form of risky sexual behaviours, none of the sexting variables was significantly associated with unprotected, i.e., condomless sex. This result is supported by the study of Currin et al. (2016) where condomless sex was also not associated with sexting behaviors. However, the result was in contrast to findings by Benotsch et al. (2013) and Crimmins \& Seigfried-Spellar (2014) which had confirmed a relationship between sexting and unprotected sex. More in-depth research is required to explore whether and how sexting leads to unprotected sex or vice versa. An increase in the frequency of sexting was associated with an increase in the number of sexual partners. This is similar to findings by Benotsch et al. (2013). Multiple sexual partners make young people probably more likely to receive and send sexts more often than having only one or no sexual partner. The frequency of sexting was also associated with sex under the influence of alcohol and drugs. Under the influence of substances, young people may feel less inhibited to engage in sexting, which could explain the higher frequency of sexting among those who used alcohol and drugs. However, the correlations obtained were weak, which indicates that other variables that the study did not control for may have contributed to the relationship between sexting and risky sexual behaviour. The small sample size might also have played a role in the weak correlations. Binary logistic regression analysis identified number of partners as the only predictor of sending sexts, however, the predictive power of this variable was very low. More empirical work is, therefore, required for the results to be confirmed. None of the risky sexual behaviours predicted whether or not participants had received sexts.

The question remains, whether indeed sexting and risky sexual behaviours are associated and, if so, whether risky sexual behaviours are a result of sexting or whether sexting is a result of risky sexual behaviours. As pointed out by Drouin et al. (2015), sexting itself is a risky behaviour that exposes young people to the potential of abuse and is associated with other forms of risky behaviours such as misuse of substances. Perhaps, young people who take risks in their sexual behaviours are also more likely to take risks in their sexting behaviours and vice versa. More research, theory-based explanations and structural equation models are needed to answer the question about the relationship and the direction of causality in the relationship between sexting and risky sexual behaviours.

\section{Limitations}

This exploratory study had three main limitations. Firstly, the participants, being university students, were a rather homogeneous group. Therefore, the results cannot be generalised to other young people in Botswana. Secondly, based on the self-report questionnaire and considering the sensitive topic in question (i.e., participants' sexuality and related behaviours), participants may have under or over-reported their engagement in sexting and risky sexual behaviours. Thirdly, the study did not control for mediating variables such as personality characteristics, stability/cohesiveness of the home/family environment, psychological bonding with parents or adjustment to the university environment. More research is needed to address these limitations.

\section{Conclusion}

In spite of the need for more research, the results of this study suggest that sexting is a common form of communication among university students in Botswana. The results also indicate that sexually active students are more likely to engage in sending sexts than sexually non-active students. The results imply that frequent sexting is associated with risky sexual behaviours, which makes sexting a relevant topic to be discussed in public health care and sex education. For example, it is crucial to educate young people about the risks involved in revealing matters of sexual intimacy through sexting as sexting can result in a loss of personal control over one's privacy once a sext is sent. Young people have to be made aware that sexting makes them vulnerable to misuse and abuse of their intimate personal information and that sexting does not make provision for later regrets or wishes to withdraw sexting content. Sex education for young people who have never known a world without the 
internet and online facilities, has to assist them to develop skills and competencies of protecting their privacy and intimacy in the digital world. Considering possible interrelatedness between sexting as a risky behaviour and risky sexual behaviour, sexting could make young people vulnerable to STDs including HIV infection, which is of particular interest in the context of Botswana, where HIV rates are high among the young generations. Empowering young people to protect their sexual intimacy from online abuse could also empower them psychologically to protect their life and to practice safe sex in order to avoid HIV infection. Parents, teachers, student counsellors, and health care providers could include the topic of sexting when discussing sexual behaviour and safe sex with young people to make them aware of the risks that sexting can impose on them.

\section{References}

Arnett, J. J. (2000). Emerging adulthood. A theory of development from the late teens through the twenties. American Psychologist, 55, 469-480.

Benotsch, E. G., Snipes, D. J., Martin, A. M. \& Bull, S. S. (2013). Sexting, substance use, and sexual risk behavior in young adults. Journal of Adolescent Health, 52, 307-313. https://doi.org/10.1016/j.jadohealth.2012.06.011

Botswana Communications Regulatory Authority (2016). Annual Report. Gaborone, Botswana.

Chalfen, R. (2009). 'It's only a picture': Sexting, 'smutty' snapshots and felony charges. Visual Studies, 24, 258-268. https://doi.org/10.1080/14725860903309203

Crimmins, D. M., \& Seigfried-Spellar, K. C. (2014). Peer attachment, sexual experiences, and risky online behaviors as predictors of sexting behaviors among undergraduate students. Computers in Human Behavior, 32, 268-275. https://doi.org/10.1016/j.chb.2013.12.012

Currin, J. M., Hubach, R. D., Sanders, C., \& Hammer, T. R. (2016). Sexting leads to "risky"sex? An analysis of sexting behaviors in a nonuniversity-based, older adult population. Journal of Sex \& Marital Therapy. Advanced online publication. https://doi.org/10.1080/0092623X.2016.1246390

Dake, J. A., Price, D. H., Mazriaz, L., \& Ward, B. (2012). Prevalence and correlates of sexting behavior in adolescents. American Journal of Sexuality Education, 7, 1-15. https://doi.org/10.1080/15546128.2012.650959

Delevi, R., \& Weisskirch, R. S. (2013). Personality factors as predictors of sexting. Computers in Human Behavior, 29, 2589-2594. https://doi.org/10.1016/j.chb.2013.06.003

Dintwat, K. F. (2010). Changing family structure in Botswana. Journal of Comparative Family Studies, 41, 281-297.

Dir, A. L., Cyders, M. A., \& Coskunpinar, A. (2013). From the bar to the bed via mobile phone: A first test of the role of problematic alcohol use, sexting, and impulsivity-related traits in sexual hook-ups. Computers in Human Behavior, 29, 1664-1670. https://doi.org/10.1016/j.chb.2013.01.039

Döring, N. (2014). Consensual sexting among adolescents: Risk prevention through abstinence education or safer sexting? Cyberpsychology: Journal of Psychosocial Research on Cyberspace, 8(1), article 9.

http://dx.doi.org/10.5817/CP2014-1-9

Drouin, M., \& Landgraff, C. (2012).Texting, sexting, and attachment in college students' romantic relationships. Computers in Human Behavior, 28, 444-449. https://doi.org/10.1016/j.chb.2011.10.015

Drouin, M., Ross, J., \& Tobin, E. (2015). Sexting: A new, digital vehicle for intimate partner aggression? Computers in Human Behavior, 50, 197-204. https://doi.org/10.1016/j.chb.2015.04.001

Drouin, M., Vogel, K. N., Surbey, A., \& Stills, J. R. (2013). Let's talk about sexting, baby: Computer-mediated sexual behaviors among young adults. Computers in Human Behavior, 29, A25-A30.

https://doi.org/10.1016/j.chb.2012.12.030

Erikson, E. H. (1968). Identity: Youth and crisis. New York: Norton.

Fako, T. T. (2005). Family life, psychological bonding and sexual activity among students in Botswana. Pula: Botswana Journal of African Studies, 19(1), 15-27. 
Ferguson, C. J. (2011). Sexting behaviors among young Hispanic women: Incidence and association with other high-risk sexual behaviors. Psychiatric Quarterly, 82, 239-243. https://doi.org/10.1007/s11126-010-9165-8

Gámez-Guadix, M., Almendros, C., Borrajo, E., \& Calvete, E. (2015). Prevalence and association of sexting and online sexual victimization among Spanish adults. Sexuality Research and Social Policy, 12, 145-154.

https://doi.org/10.1007/s13178-015-0186-9

Gordon-Messer, D., Bauermeister, J., A., Grodzinski, A., \& Zimmerman, M. (2013). Sexting among young adults. Journal of Adolescent Health, 52, 301-306. https://doi.org/10.1016/j.jadohealth.2012.05.013

Henderson, L., \& Morgan, E. (2011). Sexting and sexual relationships among teens and young adults. McNair Scholars Research Journal, 7(1), 31-39.

Hudson, H. K., Fetro, J. V., \& Ogletree, R. (2014). Behavioral indicators and behaviors related to sexting among undergraduate students. American Journal of Health Education, 45, 183-195.

https://doi.org/10.1080/19325037.2014.901113

Klettke, B., Hallford, D. J., \& Mellor, D. J. (2014). Sexting prevalence and correlates: A systemic literature review. Clinical Psychology Review, 34, 44-53. https://doi.org/10.1016/j.cpr.2013.10.007

Lesitaokana, W. O. (2014a). Young people and mobile phone technology in Botswana. In J. Wyn \& H. Cahill (Eds.). Handbook of children and youth studies (pp. 801-813). Singapore: Springer.

Lesitaokana, W. O. (2014b). Mobile phone consumption among students in Botswana. Lonaka - Journal of Learning and Teaching, 2014 issue, 31-37.

Levine, D. (2013). Sexting: A terrifying health risk ... or the new normal for young adults. Journal of Adolescent Health, 52, 257-258. https://doi.org/10.1016/j.jadohealth.2013.01.003

Lippman, J. R., \& Campbell, S. W. (2014). Damned if you do, damned if you don't ... if you are a girl: Relational and normative contexts of adolescent sexting in the United States. Journal of Children and Media, 8, 371-386.

https://doi.org/10.1080/17482798.2014.923009

Ministry of Education and Skills Development (2015). Department of Tertiary Education Financing. Gaborone, Botswana.

Ott, M. A., Millstein, S. G., Ofner, S., \& Halpern-Felsher, B. L. (2006). Greater expectations: Adolescents' positive motivations for sex. Perspective on Sexual Reproductive Health, 38, 84-89. https://doi.org/10.1111/j.19312393.2006.tb00064.x

Samimi, P., \& Alderson, K. G. (2014). Sexting among undergraduate students. Computers in Human Behavior, 31, 230-241. https://doi.org/10.1016/j.chb.2013.10.027

Seal, D. W., \& Ehrhardt, A. A. (2003). Masculinity and urban men: perceived scripts for courtship, romantic, and sexual interactions with women. Culture, Health \& Sexuality, 5, 295-319.

https://doi.org/10.1080/136910501171698

Seiffge-Krenke, I. (2003). Testing theories of romantic development from adolescence to young adulthood: Evidence of a developmental sequence. International Journal of Behavioral Development, 27, 519-531.

https://doi.org/10.1080/01650250344000145

Silva, R. B. R., Teixeira, C. M., Vasconcelos-Raposo, J., \& Bessa, M. (2016). Sexting: Adaptation of sexual behaviour to modern technologies. Computers in Human Behavior, 64, 747-753. https://doi.org/10.1016/j.chb.2016.07.036

Strassberg, D. S., Rullo, J. E., \& Mackaronis, J. E. (2014). The sending and receiving of sexually explicit cell phone photos ("Sexting") while in high school: One college's students' retrospective reports. Computers in Human Behavior, 41, 177-183. https://doi.org/10.1016/j.chb.2014.09.008 
UNAIDS (2013). Global Report. UNAIDS Report on the global AIDS epidemic 2013. Joint United Nations Programme.

Van Ouytsel, J., Van Gool, E., Walrave, M., Ponnet, K., \& Peeters, E. (2015). Sexting: adolescents' perceptions of the applications used for, motives for, and consequences of sexting. Journal of Youth Studies. Advanced online publication. https://doi.org/10.1080/13676261.2016.1241865

Weisskirch, R. S., \& Delevi, R. (2011). "Sexting" and adult romantic attachment. Computers in Human Behavior, 27, 1697-1701. https://doi.org/10.1016/j.chb.2011.02.008

Wiederhold, B. K. (2011). Should adult sexting be considered for the DSM? Cyberpsychology, Behavior and Social Networking, 14, 481-481. https://doi.org/10.1089/cyber.2011.1522

Woodward, V. H., Evans, M., \& Brooks, M. (2016). Social and psychological factors of rural youth sexting: An examination of gender-specific models. Deviant Behavior, 38, 461-476.

https://doi.org/10.1080/01639625.2016.1197020

\section{Correspondence to:}

I.E. Plattner

Department of Psychology

University of Botswana

Private Bag 00705

Gaborone

Botswana

Email: plattner(at)mopipi.ub.bw and plattnerlisa5(at)gmail.com

\section{About Authors}

Mr. Obakeng L. Makgale is a psychology and environmental science graduate from the University of Botswana. Currently, he works as an intern for environmental control for the Kazungula Bridge Project Consultants. His research interests focus on behaviour in relation to the environment and on the influence of sexting on young adults' behaviours and well-being.

Dr. I. E. Plattner is Professor of Psychology at the University of Botswana. Her research interests are related to developmental psychology of adulthood, psychological aspects of HIV and AIDS, and the psychology of work.

Editorial record: First submission received on September 2, 2016. Revisions received on December 7, 2016, March, 13, 2017, and May 20, 2017. Accepted for publication on May 23, 2017. 